\title{
Optoactivation of Locus Ceruleus Neurons Evokes Bidirectional Changes in Thermal Nociception in Rats
}

\author{
Louise Hickey, ${ }^{1}$ Yong Li, ${ }^{1}$ Sarah J. Fyson, ${ }^{1}$ Thomas C. Watson, ${ }^{5}$ Ray Perrins, ${ }^{1}$ James Hewinson, ${ }^{4}$ Anja G. Teschemacher, ${ }^{1}$ \\ Hidemasa Furue, ${ }^{3}$ Bridget M. Lumb, ${ }^{1}$ and Anthony E. Pickering ${ }^{1,2}$ \\ ${ }^{1}$ School of Physiology and Pharmacology, University of Bristol, Bristol BS8 1TD, United Kingdom, ${ }^{2}$ Department of Anesthesia, University Hospitals Bristol, \\ Bristol BS2 8HW, United Kingdom, ${ }^{3}$ Department of Information Physiology, National Institute for Physiological Sciences, Myodaiji, Okazaki 444-8787, \\ Japan, ${ }^{4}$ Wellcome Trust Sanger Institute, Cambridge CB10 1SA, United Kingdom, and ${ }^{5}$ Sorbonne Universités, Université Pierre et Marie Curie Paris 6, Unité \\ Mixte de Recherche-Scientifique 8246, Neuroscience Paris Seine, Navigation Memory and Aging team, F-75005 Paris, France
}

Pontospinal noradrenergic neurons are thought to form part of a descending endogenous analgesic system that exerts inhibitory influences on spinal nociception. Using optogenetic targeting, we tested the hypothesis that excitation of the locus ceruleus (LC) is antinociceptive. We transduced rat LC neurons by direct injection of a lentiviral vector expressing channelrhodopsin 2 under the control of the PRS promoter. Subsequent optoactivation of the LC evoked repeatable, robust, antinociceptive $\left(+4.7^{\circ} \mathrm{C} \pm 1.0, p<0.0001\right)$ or pronociceptive $\left(-4.4^{\circ} \mathrm{C} \pm 0.7, p<0.0001\right)$ changes in hindpaw thermal withdrawal thresholds. Post hoc anatomical characterization of the distribution of transduced somata referenced against the position of the optical fiber and subsequent further functional analysis showed that antinociceptive actions were evoked from a distinct, ventral subpopulation of LC neurons. Therefore, the LC is capable of exerting potent, discrete, bidirectional influences on thermal nociception that are produced by specific subpopulations of noradrenergic neurons. This reflects an underlying functional heterogeneity of the influence of the LC on the processing of nociceptive information.

Key words: ChannelRhodopsin2; endogenous analgesia; lentiviral vector; locus ceruleus; noradrenergic; pain

\section{Introduction}

The degree of pain perceived in response to a given noxious stimulus is greatly influenced by the context within which the injury occurs (Melzack et al., 1982). In part, this variation in perception is due to differential engagement of endogenous analgesic mechanisms within the CNS that act to modulate pain (Ossipov et al., 2010). Since the original report that electrical stimulation of the midbrain produces profound analgesia (Reynolds, 1969), much attention has been focused on descending control systems, which can influence the spinal transmission of noxious inputs (Millan, 2002; Fields, 2004). The noradrenaline (NA)containing neurons of the locus ceruleus (LC) and the $\mathrm{A} 5$ and A7 cell groups in the pons have been implicated as key components of this descending control system (Jones, 1991; Pertovaara, 2006).

Received Nov. 18, 2013; revised Jan. 17, 2014; accepted Feb. 7, 2014.

Author contributions: H.F., B.L., and A.E.P. designed research; L.H.,Y.L., S.J.F., R.P., and J.H. performed research; A.G.T. contributed unpublished reagents/analytic tools; L.H., Y.L., S.J.F., T.C.W., R.P., and A.E.P. analyzed data; L.H. and A.E.P. wrote the paper.

This work was supported by the Wellcome Trust and the British Heart Foundation. A.E.P. is a Wellcome Senior Clinical Research Fellow.

The authors declare no competing financial interests.

This article is freely available online through the J Neurosci Author Open Choice option.

Correspondence should be addressed to A.E. Pickering, School of Physiology and Pharmacology, Medical Sciences

Building, University of Bristol, Bristol BS8 1TD, UK. E-mail: Tony.Pickering@bristol.ac.uk.

DOI:10.1523/JNEUROSCI.4835-13.2014

Copyright $\odot 2014$ Hickey et al.

This is an Open Access article distributed under the terms of the Creative Commons Attribution License (http://creativecommons.org/licenses/by/3.0), which permits unrestricted use, distribution and reproduction in any medium provided that the original work is properly attributed.
Although the LC sends projections throughout the neuraxis, most pain studies have concentrated upon the axonal projections to the spinal dorsal horn. These have been shown to release NA (Crawley et al., 1979; Hentall et al., 2003) that acts via $\alpha 2$ adrenoceptors to inhibit both primary afferents and second order projection neurons (Reddy et al., 1980; Hammond and Yaksh, 1984; North and Yoshimura, 1984; Jones and Gebhart, 1986b; Miller and Proudfit, 1990; Kawasaki et al., 2003; Sonohata et al., 2004). Electrical or chemical stimulation of the LC has been shown to be analgesic in a number of acute pain models (Jones and Gebhart, 1986a, 1986b; Miller and Proudfit, 1990; Jones, 1991; West et al., 1993). In addition, in chronic neuropathic pain models, there are plastic changes in the NAergic innervation of the spinal dorsal horn (Hughes et al., 2013) and increases in $\alpha 2$-adrenoceptor sensitivity (Ma and Eisenach, 2003; Hayashida et al., 2008).

Despite this knowledge of the analgesic potential of the pontospinal NAergic system; the use of systemic $\alpha 2$-adrenergic agonists to mimic its action in the treatment of pain is limited by a confounding side effect profile including sedation and hypotension (Pertovaara, 2006). The sedation can be reduced by longterm intrathecal infusion (Hassenbusch et al., 2002), but this is reserved for the most severe patients because it is expensive to deploy and can be associated with complications. Similarly, NA reuptake inhibitors, although moderately efficacious for chronic pain (Finnerup et al., 2010), are likewise limited by side effects that are largely a consequence of interactions with other central NAergic functions. Therefore, the potential of the descending 
NAergic system to suppress pain has not been successfully harnessed therapeutically.

We have demonstrated previously that pontospinal NAergic neurons can be selectively and effectively retrogradely transduced using an adenoviral vector with a catecholaminergicselective promoter (Howorth et al., 2009a) and that their inhibition, through expression of a potassium conductance, can produce thermal and inflammatory hyperalgesia (Howorth et al., $2009 b$ ). Here, we tested the hypothesis that direct activation of NAergic neurons of the LC using a selective lentiviral vector (LV)-mediated optogenetic approach produces analgesia. We show that activation of the LC can exert potent and temporally discrete antinociceptive and pronociceptive effects on the response to thermal stimulation. These contrasting actions are elicited from different subgroups of the neurons, indicating an underlying functional heterogeneity of the influence of the LC on the processing of nociceptive information.

\section{Materials and Methods}

Experimental procedures. Experiments were performed on male Wistar rats. All procedures conformed to the UK Animals (Scientific Procedures) Act of 1986 and were approved by our institutional ethical review committee. Animals were housed under a standard $12 \mathrm{~h}$ light/dark cycle with ad libitum access to food and water.

LV constructs and preparation. The study used two LV vectors: LV-sPRShChR2 (H134R)-EYFP and LV-sPRS-hChR2(H134R)-mCherry, differing only in the fluorophore fused to the human codon-optimized H134R variant of ChannelRhodopsin2 (ChR2; Fig. 1A; Boyden et al., 2005). Both LVs use the 240-bp PRSx8 promoter sequence (Hwang et al., 2001) that restricts the expression of the transgene to a subset of neurons that express the Phox 2 transcription factor, which are predominantly catecholaminergic (Tiveron et al., 1996; Brunet and Pattyn, 2002). We used a transcriptional amplification strategy (Liu et al., 2006) to enhance expression of the ChR2 (sPRS). The methods for LV production were as described previously in detail (Coleman et al., 2003; Hewinson et al., 2013). In short, this is an HIV-1-based vector pseudotyped with vesicular stomatitis virus glycoprotein. The LVs were produced by cotransfection of Lenti-X293T cells (Clontech) with the shuttle vector pTYF-sPRShChR2(H134R)-EYFP or pTYF-sPRS-hChR2(H134R)-mCherry, along with a packaging vector, $\mathrm{pNHP}$, and the envelope plasmid pHEF-VSVG. The virus was collected from the supernatant and concentrated by ultracentrifugation. The titer, measured in transducing units $(\mathrm{TU}) / \mathrm{ml}$, was assayed for each batch by establishing the infection rate of an LV produced in parallel and expressing placental alkaline phosphatase (Hewinson et al., 2013). The LV was used undiluted for microinjection at a titer of $2-3 \times 10^{10} \mathrm{TU} / \mathrm{ml}$ depending upon the batch ( 4 batches were used in the course of the experiments).

Pontine LV injection. Stereotaxic injections of LVs were made into the dorsal pons in the region of the LC. The procedures for viral vector injections have been described in detail previously (Lonergan et al., 2005; Howorth et al., 2009a). In brief, rats were anesthetized (intramuscularly or intraperitoneally) with ketamine ( $5 \mathrm{mg} / 100 \mathrm{~g}$, Vetalar; Pharmacia) and medetomidine (30 $\mu \mathrm{g} / 100 \mathrm{~g}$, Domitor; Pfizer) until loss of paw withdrawal reflex. The animal was placed in a stereotaxic frame and core temperature was maintained at $37^{\circ} \mathrm{C}$ using a homeothermic blanket (Harvard Apparatus). Aseptic surgical techniques were used throughout.

To transduce LC neurons directly before pontine brain slice/working heart brainstem (WHBP) preparations, LV injections were made into postnatal day 17 (P17)-P19 Wistar rats using a microcapillary pipette (calibrated in $1 \mu \mathrm{l}$ intervals; Sigma) with a tip diameter of $20 \mu \mathrm{m}$ backfilled with vector (Fig. 1A). Unilateral or bilateral injections (each 250 $\mu \mathrm{m}$ apart in the dorsoventral axis) of LV (250 nl/per injection of LV over $2 \mathrm{~min}$ ) were made at 4 sites along a single track with the following coordinates: $\lambda-1 \mathrm{~mm}, \mathrm{~L} 1 \mathrm{~mm}, 4.5-5.5 \mathrm{~mm}$ below the brain surface. All WHBP experiments and the initial pontine slice experiments $(n=3)$ were done with the LV-sPRS-hChR2(H134R)-EYFP; the mCherry-expressing vector was used for the remainder of the slice experiments because this allowed the neurons to be visualized without activation of ChR2.

To transduce LC neurons before cutaneous thermal stimulation, injections of LV were made in Wistar rats (250-275 g, $n=37$; Charles River Laboratories) at the following coordinates: $\lambda-2.1 \mathrm{~mm}, \mathrm{~L} 1.2 \mathrm{~mm}$, and $3 \times$ injections of LV $(300 \mathrm{nl})$ at $5.5-6.0 \mathrm{~mm}$ deep from brain surface with a $10^{\circ}$ rostral angulation. After LV injection, a guide cannula was implanted over the injection site (C313G; Plastics One) and secured to the skull with dental cement/skull screw (Zhang et al., 2010). The guide cannula was closed with a dummy cap until the time of the experiment between 2 and 3 weeks after transduction. Sixty-three percent of the animals used in heat ramp experiments received LV-sPRShChR2(H134R)-mCherry and 37\% received LV-sPRS-hChR2(H134R)EYFP. There was no difference in the proportion of animals showing antinociception versus pronociception with the different vectors.

After injections/implantation, anesthesia was reversed with atipamezole (Antisedan, $0.1 \mathrm{mg} / 100 \mathrm{~g}$, i.p.; Pfizer) and buprenorphine was given for pain relief (Temgesic, $2 \mu \mathrm{g} / 100 \mathrm{~g}$, s.c.; Schering-Plough). Animals showed a rapid functional recovery from anesthesia and surgery.

Pontine slices. Pontine slices were prepared from juvenile Wistar rats (P24-P40, $n=13,1-3$ weeks after LV transduction), which were terminally anesthetized with halothane before decapitation. The brainstem was removed and bathed in ice-cold cutting solution (similar to the recording solution but $\mathrm{NaCl}$ was reduced to $85 \mathrm{~mm}$ and substituted with sucrose $58.4 \mathrm{~mm})$. Slices of the pons were cut $(250-350 \mu \mathrm{m}$ thick coronal or longitudinal) using a vibratome (Linearslicer Pro 7; DSK) in cold $\left(4^{\circ} \mathrm{C}\right)$ cutting solution. Slices were kept at room temperature in carbogenated recording solution (composition is provided in the "Electrophysiology" section below) for at least $1 \mathrm{~h}$ before recording.

Electrophysiology. Pontine slices were transferred into the recording chamber of an upright fluorescence microscope (DMLFSA; Leica Microsystems), superfused with artificial CSF containing the following (in mu): $126 \mathrm{NaCl}, 2.5 \mathrm{KCl}, 26 \mathrm{NaHCO}_{3}, 1.25 \mathrm{NaH}_{2} \mathrm{PO}_{4}, 2 \mathrm{MgCl}_{2}, 2 \mathrm{CaCl}_{2}$, and 10 D-glucose saturated with $95 \% \mathrm{O}_{2} / 5 \% \mathrm{CO}_{2}, \mathrm{pH} 7.3$, osmolality 290 $\mathrm{mOsm} / \mathrm{L}, 35^{\circ} \mathrm{C}$ at a rate of $2-3 \mathrm{ml} \mathrm{min}^{-1}$. Patch pipettes (resistances of 4-6 M $\Omega$ ) were filled with internal solution containing the following (in $\mathrm{mm}$ ): $130 \mathrm{~K}$-gluconate, $10 \mathrm{KCl}, 10 \mathrm{Na}$-HEPES, 4 MgATP, 0.2 EGTA, and $0.3 \mathrm{Na}_{2} \mathrm{GTP}$. All membrane potentials were corrected for a junction potential of $13 \mathrm{mV}$. Fluorescent transduced LC neurons (EYFP/mCherry) were identified and whole-cell recordings were then obtained under gradient contrast illumination (Dodt and Zieglgänsberger, 1990). Once confirmed as fluorescent, the cells were not exposed to epilumination via the objective until after the whole-cell patch-clamp recordings were completed. Recordings were made in current-clamp or voltage-clamp mode and current pulses were injected to examine the current-voltage and current-spike frequency relationships (Axopatch 1D amplifier; Molecular Devices). The signal was filtered at $3 \mathrm{kHz}$, digitized at $10 \mathrm{kHz}$, and stored using Spike 2 software (Cambridge Electronic Design). Light was pulsed onto the cells ( $0.1-5 \mathrm{~mW}$ for $20 \mathrm{~ms}$ to $10 \mathrm{~s}$ ) using a focally placed optical fiber proximate to the recorded cell (400 $\mu \mathrm{m}$ in diameter) pigtailed to a $473 \mathrm{~nm}$ LED source (Doric).

WHBP. The WHBP was used to examine the responses of LC neurons to optoactivation in an in vivo-like preparation. Preparations were made from LV-transduced Wistar rats aged 24-30 d $(n=6)$ according to previously published methods (Paton, 1996; Pickering et al., 2003; McAllen et al., 2011). In brief rats, were deeply anesthetized with halothane, bisected subdiaphragmatically, exsanguinated, cooled by immersion in $5-10^{\circ} \mathrm{C}$ Ringer's solution containing the following (in mM): $125 \mathrm{NaCl}, 24$ $\mathrm{NaHCO}_{3}, 3 \mathrm{KCl}, 2.5 \mathrm{CaCl}_{2}, 1.25 \mathrm{MgSO}_{4}, 1.25 \mathrm{KH}_{2} \mathrm{PO}_{4}$, and 10 dextrose, $\mathrm{pH}$ 7.35-7.4 after carbogenation, before a precollicular decerebration and cerebellectomy to expose the dorsal surface of the pons. While still cold, the phrenic nerve and descending aorta were dissected free and a bilateral pneumonectomy was performed. The preparation was then transferred to a recording chamber and retrogradely perfused with Ficoll-70 (1.25\%) containing carbogenated aCSF $\left(32^{\circ} \mathrm{C}\right)$ through a double lumen cannula inserted into the descending thoracic aorta. As the preparation warmed and brainstem perfusion was reestablished, respiratory movements returned and the preparation was paralyzed with vecuronium $(2 \mu \mathrm{g} / \mathrm{ml})$. Preparation viability was assessed by the presence of 
A

Stereotaxic injection of lentiviral vector to LC
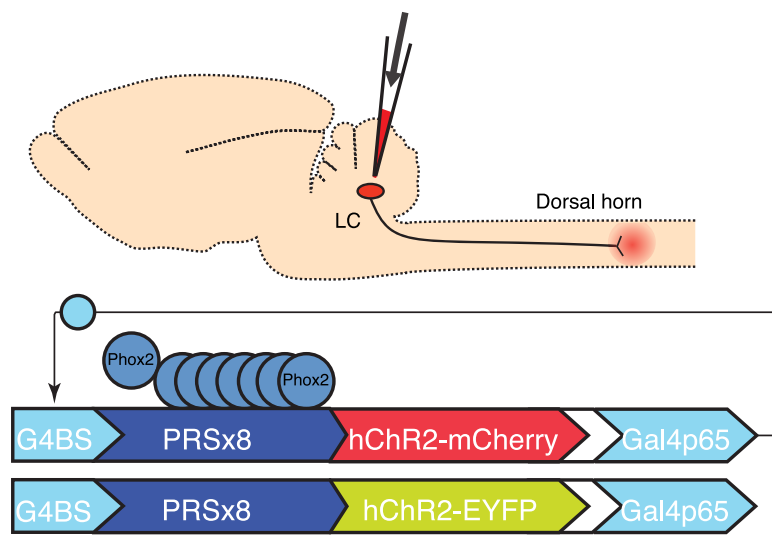

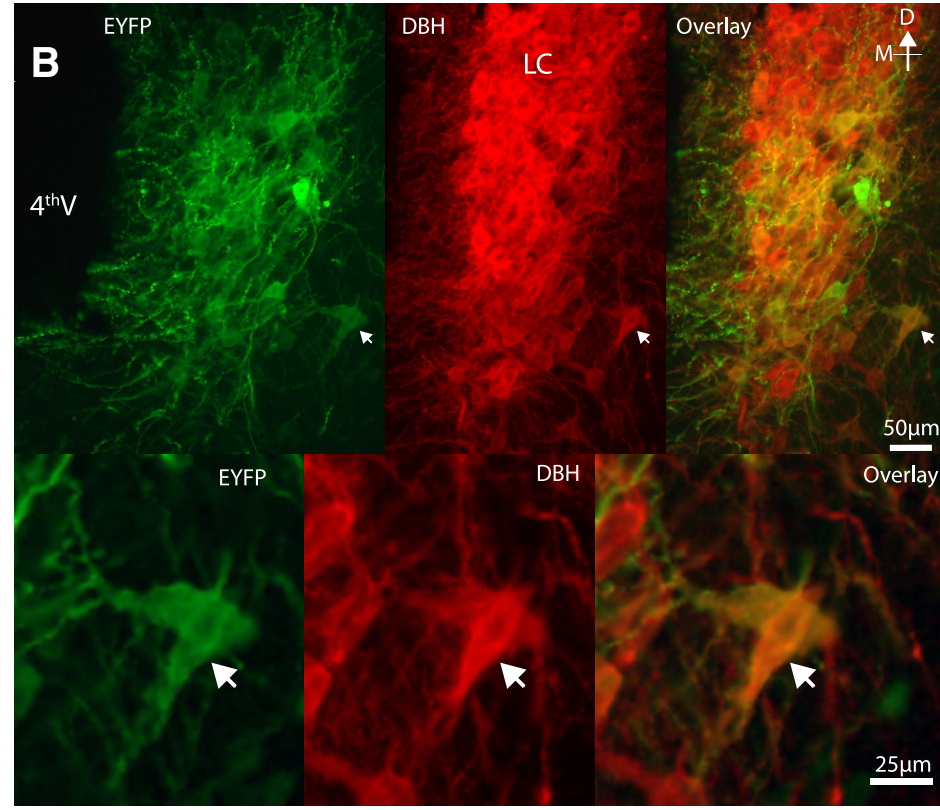

$-56 \mathrm{mV}-$

D

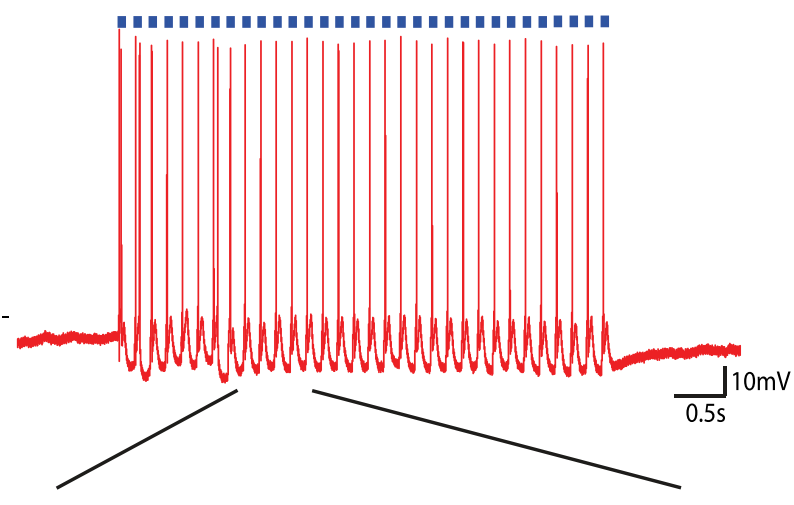

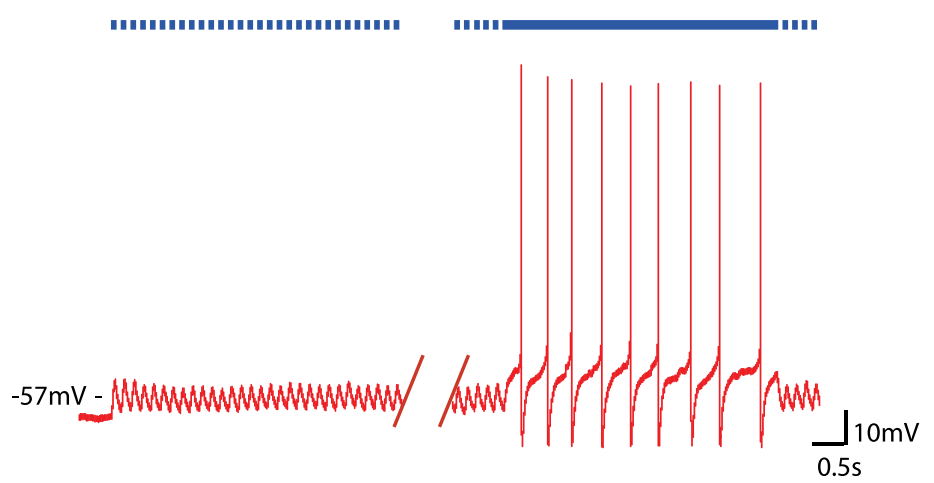

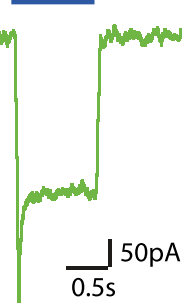

\section{E} $0.5 \mathrm{~s}$

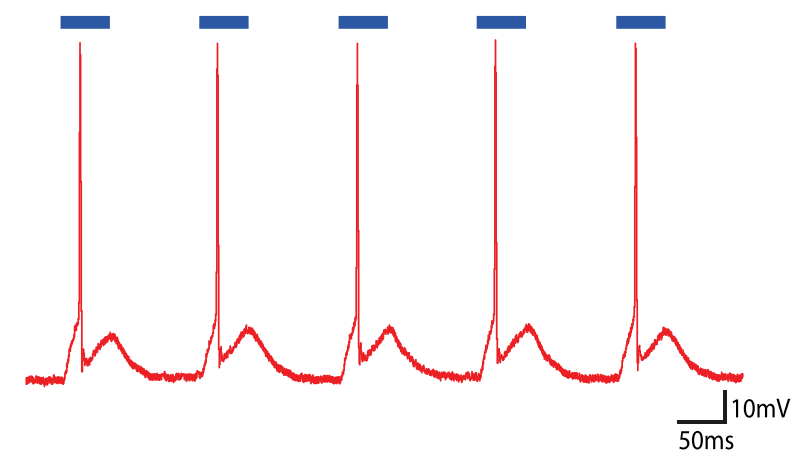

Figure 1. Selective and functional expression of hChR2 in rat locus ceruleus neurons. A, Schematic of experimental approach. LV-sPRS-hChR2(H134R)-mCherry or LV-sPRS-hChR2(H134R)-EYFP is injected directly into the LC. B, Two weeks after unilateral LC injection of LV-sPRS-hChR2(H134R)-EYFP, there is robust, selective expression in NAergic neuronal somata and processes (arrowed cells on edge of $\mathrm{LC}$ shown magnified beneath). EYFP expression (green), DBH immunoreactivity (red), and overlaid images (right). $4^{\text {th }} V$, Fourth ventricle. $C$, Voltage-clamp recordings from transduced LC neurons in brainstem slices showed inward currents to blue light, showing a characteristic fast desensitization typical of hChR2 (H134R; $473 \mathrm{~nm}$ light, 1-5 mW, Vhold -60 mV). D, Pulses of blue light $(4.5 \mathrm{~mW}, 50 \mathrm{~ms}$ ) reliably evoked action potential trains in the same neuron as $\mathbf{C}$ at a range of frequencies (up to $10 \mathrm{~Hz}$ ). $\boldsymbol{E}$, In some transduced neurons, pulsed illumination ( 50 $\mathrm{ms}, 5 \mathrm{~mW}$ ) only produced subthreshold depolarizations, whereas constant illumination of the same intensity ( $5 \mathrm{~mW}$ ) brought the neuron to threshold.

ramping phrenic nerve discharge recorded with a suction electrode and robust responses to cardiorespiratory reflex activation.

Extracellular recordings were made (using a custom-built AC amplifier) from neurons in the LC using glass microelectrodes filled with $1 \mathrm{M}$ $\mathrm{NaCl}$ (resistance $8-15 \mathrm{M} \Omega$ ). The signal was band-pass filtered $(200 \mathrm{~Hz}$ to $3 \mathrm{kHz}$ ), digitized at $10 \mathrm{kHz}$ (micro1401; Cambridge Electronic Design), and stored on a PC for analysis with Spike2 software. Neurons were optoactivated by light pulses (445 nm diode laser, Omicron Phoxx, $0.1-15 \mathrm{~mW}, 10 \mathrm{~ms}$ to $10 \mathrm{~s})$ from an optical fiber $(200 \mu \mathrm{m}$ core, multimode; Thorlabs) placed over the dorsal surface of the pons or inserted up to $300 \mu \mathrm{m}$ into the tissue. At the end of the experiment, pontine tissue was fixed in $4 \%$ paraformaldehyde for $48 \mathrm{~h}$ before sucrose cryoprotection 

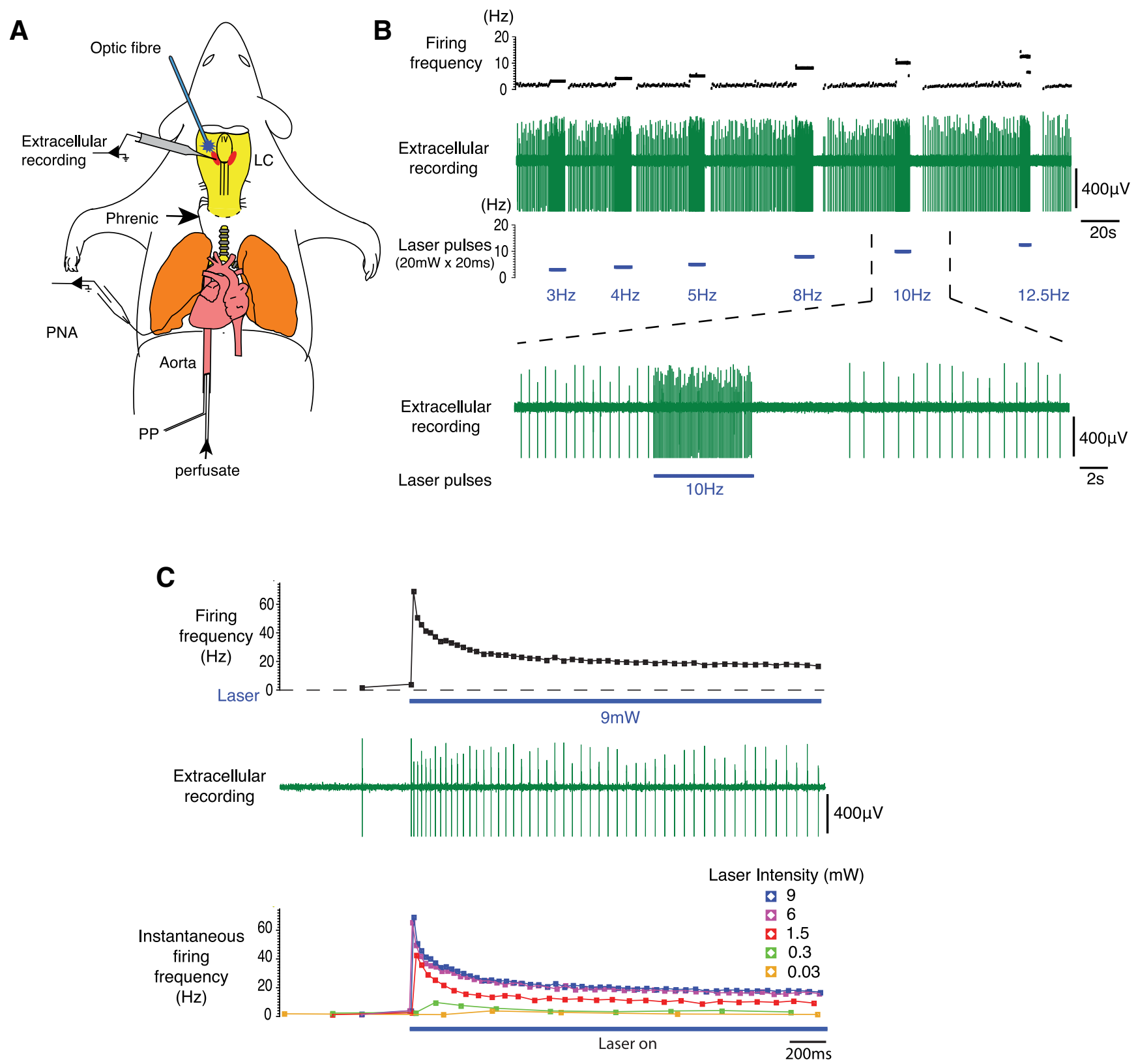

Figure 2. Optoactivation of locus ceruleus neurons in the working heart brainstem preparation. A, Rats (P21) received a unilateral injection of $L V$ into the LC. After 1-3 weeks, extracellular recordings were made from $\mathrm{LC}$ neurons in a decerebrate (and cerebellectomized), artificially perfused preparation that allows direct access to the floor of the fourth ventricle to study the cells in a functionally connected network (Paton, 1996). PNA, Phrenic nerve activity; PP, perfusion pressure. B, Action potential trains recorded from a spontaneously active LC neuron expressing LV-sPRShChR2(H134R)-EYFP. Pulsed illumination ( $\lambda 445 \mathrm{~nm}, 20 \mathrm{~mW}, 20 \mathrm{~ms}$ pulse, 3-12.5 Hz) over transduced neurons produced temporally precise activation, followed by a refractory period. At higher stimulus frequencies $(>8 \mathrm{~Hz})$, the neuron started to fail to follow each individual stimulus, resulting in a fall in frequency seen in the instantaneous firing frequency plots. $C$, The same neuron responded to continuous illumination with a prolonged increase in firing frequency (response to $9 \mathrm{~mW}$ shown in the top two panels). This was seen in response to lower light intensities and could produce a higher level of maintained neuronal discharge than pulsed stimulus protocols (instantaneous firing frequency plots shown overlaid for stimuli from 0.03 to $9 \mathrm{~mW}$ ). It was also apparent that the LC neurons show accommodation to the stimulus.

( $30 \%$ overnight). Coronal sections were cut on a freezing microtome (40 $\mu \mathrm{m})$ and processed for dopamine $\beta$-hydroxylase (DBH) as described in Immunohistochemistry, below.

Cutaneous stimulation with heat ramps. LC-transduced $(n=37)$ and naive Wistar rats $(n=12)$ were anesthetized with isofluorane $(1.5-4 \%)$ until loss of paw withdrawal reflex. The external jugular vein was cannulated and the animal was switched to an intravenous anesthetic (Alfaxalone, $10 \mathrm{mg} / \mathrm{ml}, 7.5-15 \mathrm{mg} / \mathrm{h}$; Vetoquinol). The carotid artery and trachea were also cannulated and, for some experiments, an intrathecal catheter (32 gauge tubing [Recathco] coupled to PE 10 tubing) was inserted at the L $4-5$ interspace through a $25 \mathrm{G}$ needle. The animal was placed in a stereotaxic frame and EMG wires (Teflon-coated stainless steel, $75 \mu \mathrm{m}$ diameter; Advent Research Materials) were inserted into the belly of biceps femoris. The signal was AC amplified (Neurolog NL-104; Digitimer), band-pass filtered (60 Hz to $5 \mathrm{kHz}$ Neurolog NL125) and digitized (at $20 \mathrm{kHz}$ ) via a micro1401 into Spike2 software (Cambridge Electronic Design).

Once the surgical procedures were completed, the anesthetic was titrated to a stable, lighter plane of anesthesia until a withdrawal reflex could be evoked by moderate pinch of the forepaw. Heat ramp stimuli were applied to the dorsal surface of the left hindpaw using a custombuilt thermal heat stimulator consisting of a heating lamp focused on a copper disc placed in contact with the foot with a surface mounted thermode (McMullan et al., 2004). The rate of heating of the hindpaw was 
adjusted to be in the range of $6.5-7.5^{\circ} \mathrm{C} \mathrm{s}^{-1}$. The temperature at the point of hindlimb withdrawal (based on onset of EMG response) was measured as the output of the assay. Ramps were applied at $8 \mathrm{~min}$ intervals to minimize the risk of sensitization. Three baseline threshold measures (within $1.5^{\circ} \mathrm{C}$ of each other) were obtained before light stimulation was tested to ensure stable recording conditions. Light stimuli ( $\lambda 445 \mathrm{~nm}, 1-30 \mathrm{~mW}$, pulsed or continuous) were applied via a bare-ended fiber optic (200 $\mu \mathrm{m}$ core, multimode; Thorlabs) lowered through the implanted guide cannula to a predetermined depth just above the left LC (4.5 $\mathrm{mm}$ deep to the brain surface). The threshold of the withdrawal response to heat ramp was rechecked after changing the fiber position to ensure that it remained stable before trials of optoactivation. The optical stimuli were initiated $60 \mathrm{~s}$ before application of the heat ramp and were terminated immediately after the ramp. If no response was seen (i.e., change in threshold of $<1.5^{\circ} \mathrm{C}$ ) with successive heat ramps, then the fiber was advanced in 500 $\mu \mathrm{m}$ steps to a maximum depth of $6.5 \mathrm{~mm}$. If no change in threshold was seen on reaching this depth, then the experiment was ended $(n=11)$. In three of these experiments, the post hoc histology showed that the implanted guide cannula was off target and these were excluded from further analysis. In the remaining eight, there was no evidence of viral transduction (no fluorophore expression), but the fiber was correctly targeted to the LC. These preparations were then used as controls for thermal withdrawal thresholds and also blood pressure changes.

Extracellular recording. Extracellular recordings of LC neurons (ipsilateral to LV injection) were obtained during preliminary heat ramp testing. A parylene-c insulated tungsten microelectrode (5 M $\Omega$; A-M systems) referenced against a sintered silver chloride pellet placed under the scalp was lowered into the left LC (5.2-6.5 $\mathrm{mm}$ deep to the brain surface). The signal was amplified (Axon Multiclamp 700A; Molecular Devices), filtered (100 $\mathrm{Hz}$ to $2-3$ $\mathrm{kHz}$ ), and data were collected as described for the WHBP. Neurons were considered to be LC if they fit several criteria: (1) a duration of action potential $\geq 1 \mathrm{~ms}$, (2) spontaneous firing with a slow firing rate of $0.5-7 \mathrm{~Hz},(3)$ a large amplitude characteristic action potential waveform, or (4) biphasic response to contralateral hindpaw pinch with activation followed by a transient silent period (as described previously; Cedarbaum and Aghajanian, 1978). Extracellular recordings were used to assay the response of LC cells to noxious thermal stimuli and then optoactivation. The baseline firing rate (in Hertz) of LC neurons was measured over a $5 \mathrm{~s}$ window (always taken $20 \mathrm{~s}$ before start of either heat or light stimuli). In those preparations $(n=5)$ examining LC responses to thermal stimuli, LC firing rate (in Hertz) was recorded over a $5 \mathrm{~s}$ time period from the onset of the burst of activity. In preparations measuring cell responses to optoactivation, the recording electrode was coupled to an optical fiber ( $150 \mu \mathrm{m}$ core; Thorlabs; Abbott et al., 2009) with its recording tip $500 \mu \mathrm{m}$ ahead of the fiber tip. Note that this assembly could not be easily maneuvered down the implanted guide cannula (usually only one recording track was possible), so these recordings were not performed routinely in the heat ramp experiments. Cells were illuminated ( $445 \mathrm{~nm}$ diode laser, Omicron Phoxx, 1-30 $\mathrm{mW}$, continuous 5-30 s) and the change in LC firing rate was compared with the baseline firing rate taken before onset of illumination.

Tissue fixation. Rats were killed with an overdose of pentobarbital (Euthatal, $20 \mathrm{mg} / 100 \mathrm{~g}$, i.p.; Merial Animal Health) and perfused transcardially with $0.9 \% \mathrm{NaCl}(1 \mathrm{ml} / \mathrm{g})$ followed by $4 \%$ formaldehyde (Sigma) in $0.1 \mathrm{~m}$ phosphate buffer ( $\mathrm{PB} ; \mathrm{pH} 7.4,1 \mathrm{ml} / \mathrm{g}$ ). The brain was removed and postfixed overnight before cryoprotection in $30 \%$ sucrose. Coronal tissue sections were cut at $40 \mu \mathrm{m}$ intervals using a freezing microtome and left free floating for fluorescence immunohistochemistry.

Immunohistochemistry. Tissue sections were washed 3 times in $0.1 \mathrm{M}$ $\mathrm{PB}$ and permeabilized in 50\% ethanol for $30 \mathrm{~min}$ before further washing. The tissue was incubated on a shaking platform with primary antibodies against dopamine $\beta$-hydroxylase (mouse anti-DBH, MAB308, 1:10,000 or $100 \mathrm{ng} / \mathrm{ml}$; Millipore), or EYFP (chicken anti-EGFP, AB13970, 1:5000 or $2 \mu \mathrm{g} / \mathrm{ml}$; Abcam) in PB with 5\% horse serum (HS) and $0.3 \%$ Triton X-100 for $12-24 \mathrm{~h}$ at room temperature. After further washing, sections were incubated for $4 \mathrm{~h}$ with appropriate secondary antibodies conjugated to fluorophores (Alexa Fluor 488 and Alexa Fluor 594 1:1000 or AMCA 
A
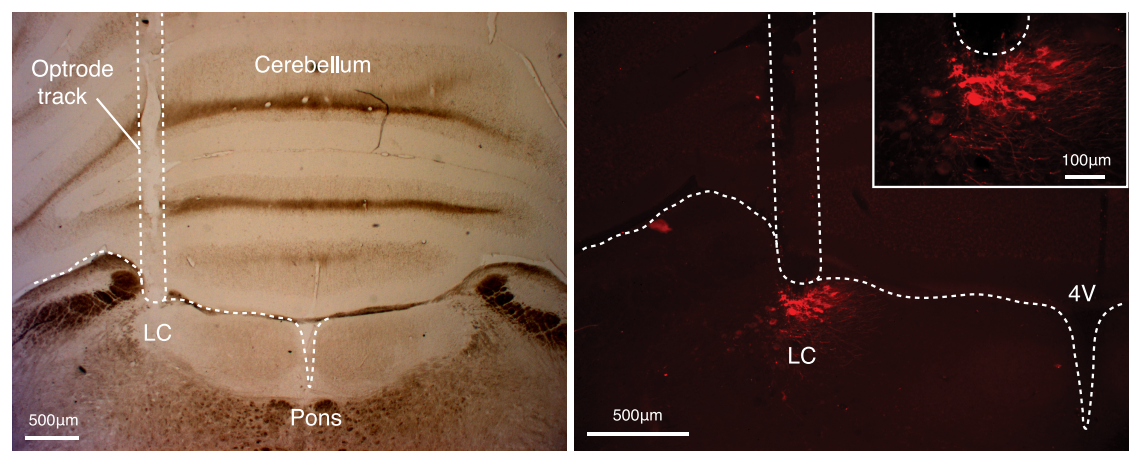

B

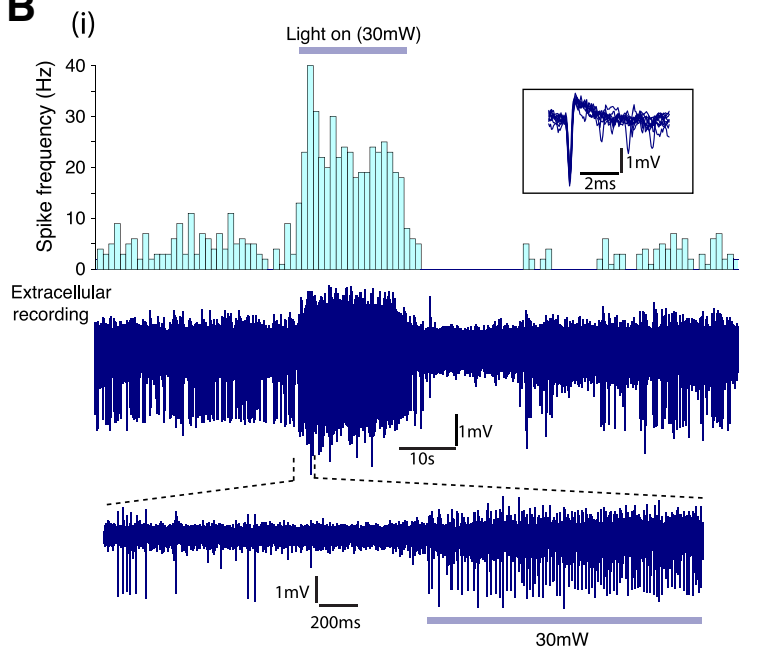

(ii)

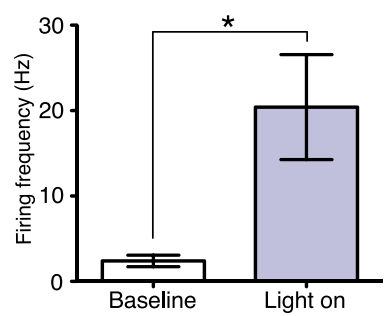

Figure 4. Targeting and optoactivation of $\mathrm{LC}$ neurons in vivo. A, Position of optical fiber (dotted white line) with respect to the $\mathrm{LC}$ is evident in the bright-field view of the cerebellum and dorsal pons. The fluorescence image of the same section showing $\mathrm{LC}$ neurons transduced with LV-sPRS-hChR2(H134R)-mCherry (red). 4V, Fourth ventricle. Bi, In vivo extracellular recording (with an optic fiber-electrode combination) from a spontaneously active LC neuron transduced with LV-sPRS-hChR2(H134R)-mCherry. Continuous illumination $(30 \mathrm{~mW}$ ) over the transduced $\mathrm{L}$ ( produced repeatable, titratable increases in neuronal discharge, followed by a period of neuronal silence that is characteristic of $\mathrm{LC}$ neurons. Bii, Pooled data showing optoactivation of $\mathrm{L} C$ neurons produced robust increases in cell activity $\left(n=5 ;{ }^{*} p<0.05\right.$, paired $t$ test).

1:200) in PB with $2 \%$ HS and $0.3 \%$ Triton X-100. Sections were washed three times before mounting. We validated the specificity of the $\mathrm{DBH}$ antibody previously (Howorth et al., 2009a). The anti-EGFP antibody has been validated by Western blot and immunocytochemistry to be specific for both EGFP and EYFP (Abcam manufacturer's datasheet). Here, it showed an overlapping distribution with EYFP-positive cell bodies and processes and amplified the signal in distal processes; no staining was seen in control brainstem tissues without viral vector injection. Negative controls were routinely run by omitting primary antibodies.

Photomicrography. Representative images were taken on a Zeiss Axioskop 2 fluorescence microscope with a Zeiss Axiocam HRC using the appropriate excitation-emission filter sets (EYFP/Alexa Fluor 488 \#10, mCherry/Alexa Fluor $594 \# 1$ and \#5, and AMCA \#02). The images were initially processed using Zeiss software (Axiocam 4.7 software),Zeiss and prepared for presentation using Adobe Photoshop CS5 with optimization of contrast/brightness as required and the addition of annotation.

Analysis. All data are presented as mean \pm SEM or median (interquartile range) as appropriate. The normality of data was assessed using the D'Agostino-Pearson test. Subsequent statistical testing was undertaken using paired and unpaired $t$ tests, one- and two-way ANOVA (with Bonferroni's posttests), and Mann-Whitney/Kruskal-Wallis (with Dunn's posttest) tests as appropriate. Data were analyzed using Prism Version 5 software (GraphPad) and differences were considered significant at $p<0.05$.

\section{Results}

Selective expression of $\mathrm{ChR} 2$ in noradrenergic LC neurons

Direct stereotaxic injection of LV-sPRShChR2(H134R)-EYFP or LV-sPRS-hChR2 (H134R)-mCherry to the LC produced selective expression of the fluorophoreChR2 construct within LC neurons (Fig. $1 A, B)$. These transduced neurons showed characteristic membrane-delimited fluorescence with strong signal from the dendrites and axonal processes, as expected of the ion channel-fluorophore construct. The expression was limited to neurons that were identified as NAergic on the basis of DBH immunocytochemistry (Fig. $1 B)$. The strength of expression increased, as judged from the fluorescence intensity and the extent of visible processes over a period of 3 weeks.

\section{Functional expression of ChR2 in LC neurons in vitro}

To confirm the functional expression of hChR2 in the LC, we transduced neurons by stereotaxic injection of LV 1-3 weeks before preparing pontine slices. Successful transduction of the neurons was confirmed by the presence of visible fluorescent somata within the boundaries of the LC in the slice. Current-clamp recordings of the transduced fluorescent neurons $(n=15)$ showed typical LC electrophysiology, indicative of good cellular health, including spontaneous action potential discharge, large action potentials, and a pronounced slow AHP. Optoactivation evoked inward currents in voltage clamp (Fig. 1C) that reversed close to zero and showed a rapid phase of desensitization, characteristic of ChR2. Current-clamp recordings showed that light pulses evoked time-locked depolarizations in all cells and action potential discharge (Fig. 1D). This pattern of optoexcitation was not seen in neurons that were not fluorescent or in transduced neurons in response to incident white light illumination. The charging of the membrane in these LC neurons typically took 20-50 ms before the threshold for spike discharge was reached. The LC neurons showed accommodation during a train of pulses with failures of spike discharge to limit the frequency of repetitive firing (typically to $<10 \mathrm{~Hz}$ ). Both pulsed and continuous illumination were effective stimuli for some cells ( $n=4 / 6$ tested with both stimuli). However, in several of these LC neurons $(n=2 / 6)$, only the application of constant light (or prolonged pulses of duration $>100 \mathrm{~ms}$ ) could bring the neuron to threshold, whereas pulsed illumination (with durations of $\leq 50 \mathrm{~ms}$ ) only produced subthreshold depolarizations (Fig. 1E). Furthermore, continuous illumination consistently increased spike discharge at lower light intensities than pulsed illumination. In all neurons, the optoexcitation was followed by a period of neuronal quiescence; the magnitude of this silent period was related to the 
duration and intensity of prior stimulation, as is characteristic of LC neurons (Aghajanian et al., 1977).

\section{Functional expression of ChR2 in LC neurons in the WHBP}

The WHBP was used to examine the responses of LC neurons to optoactivation in an in vivo-like preparation to test whether their activity could be driven in a more intact setting with competing ongoing synaptic drives and compensatory mechanisms (Fig. 2). Extracellular recordings in the WHBP showed that pulsed illumination over the transduced LC could produce temporally locked activation of neurons $(n=6$; Fig. $2 B)$. These extracellularly recorded LC neurons faithfully generated action potentials in response to pulsed optoactivation (at 1-2 $\mathrm{Hz}$ with pulses of 20-30 ms duration, 20 $\mathrm{mW})$. However, for each cell, failures of optoactivation were observed at higher stimulus frequencies of between 2 and 10 $\mathrm{Hz}$ that limited the maximum discharge frequency. Constant illumination of the same neurons produced robust increases in firing frequency (Fig. 2C) at relatively lower light intensities. Furthermore, the peak firing frequency that could be attained was higher than that seen with pulsed stimulation (reaching a peak of $29 \pm 14 \mathrm{~Hz}, n=5$ ), although, in every case, the neurons exhibited a degree of accommodation to these stimuli. As in slices, the periods of optoexcitation were followed by a refractory period $(7.9 \pm 2.1 \mathrm{~s})$ when spontaneous action potential discharge was inhibited.

\section{LC optoactivation strongly modulates thermal nociception in vivo}

The withdrawal response to a thermal

heat ramp stimulus applied to the hindpaw of anesthetized adult rats was used to assay the effect of LC optoactivation on nociception (Fig. 3). Extracellular recordings of LC neurons were made in vivo to confirm the coordinates for subsequent optoactivation experiments ( $n=3$ rats) and to characterize their responses to heat ramp stimuli ( $n=5$ rats). LC neurons were found from 5.0 to $6.5 \mathrm{~mm}$ ventral to the cerebellar surface and were recognizable by their characteristic spike shape, spontaneous activity, and biphasic response to paw pinch, which was characteristically stronger in response to stimuli applied to the contralateral paw (Cedarbaum and Aghajanian, 1978; Sugiyama et al., 2012). Application of heat ramp stimuli to the ipsilateral hindpaw triggered a phasic burst of firing as the thermal stimulus approached the noxious range and triggered a withdrawal response in all LC neurons tested (from a baseline mean rate of $2.5 \pm 0.7$ to $7.2 \pm 1.9$ $\mathrm{Hz}, p=0.048$, paired $t$ test, $n=6$ cells; Fig. 3 ). This increase in LC firing was immediately followed by a characteristic refractory period before returning to baseline firing levels after the stimulus.

For the in vivo optoactivation experiments, animals were transduced with hChR2 by injection of vector 3-4 weeks earlier
B

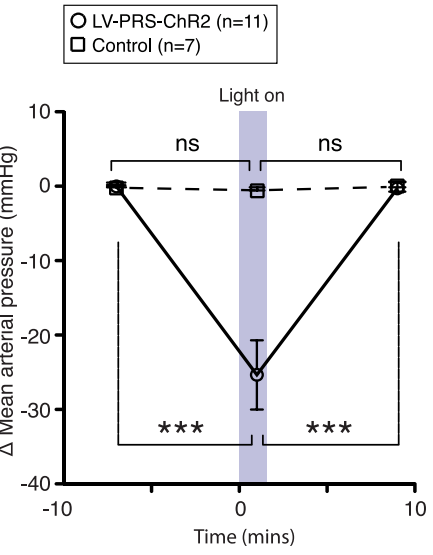

(iii) (ii)
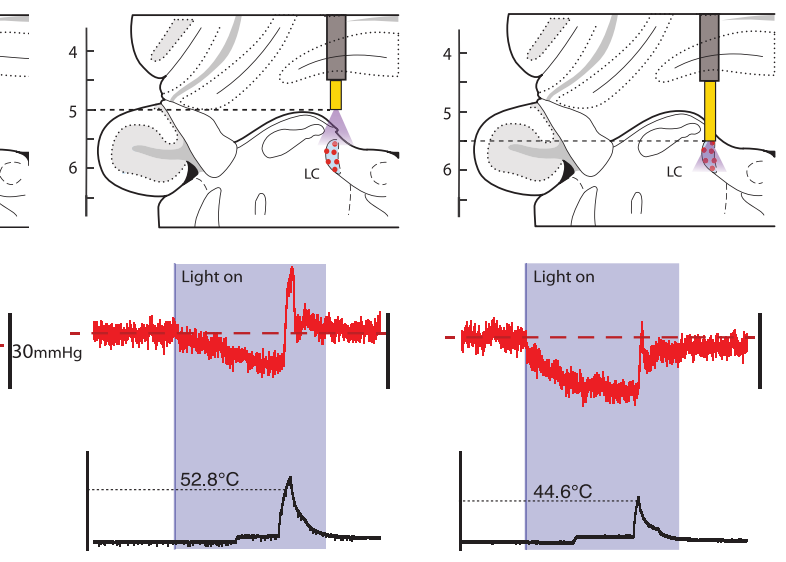

Figure 5. Optoactivation of $\mathrm{L} C$ produces a graded fall in arterial blood pressure. $\boldsymbol{A}$, Temporally discrete depressor effect on illumination of the LC ( $6-30 \mathrm{~mW}$, blue box). Arrow indicates blood pressure response to application of the noxious thermal heat ramp stimulus to the vancing the fiber to its final position ( $5.5 \mathrm{~mm}$ deep), we see a larger depressor response now accompanied by a reduction in the threshold for withdrawal. Note that with each heat ramp stimulus, there is a corresponding transient pressor effect.

and had a guide cannula implanted above the LC to direct the optical fiber. Lowering a combined optical fiber-tungsten electrode down the cannula (Fig. $4 A$ ) allowed the effect of optoactivation to be seen in vivo. LC cells were driven strongly by continuous illumination $(30 \mathrm{~mW}$, firing rate of LC neurons increased from $2.4 \pm 0.7$ to $20.4 \pm 6.1 \mathrm{~Hz}, p=0.043$, paired $t$ test, $n=5$ cells; Fig. $4 B$ ), which was consistent with our observations in the WHBP. In each case, this was followed by a period of relative quiescence once the illumination ceased, but the responses were fully recapitulated on repeat optoactivation. Therefore, based on our in vitro and in situ experiences with pulsed optoactivation of LV-transduced LC neurons (showing limited frequency response), we elected to standardize on a continuous illumination protocol for the subsequent in vivo experiments because this allowed us to more closely mimic the stimulation protocol $(50-100 \mathrm{~Hz}$ applied for periods of up to $1 \mathrm{~min}$ ) before noxious stimulation used in previous studies of LC antinociceptive effects (Jones and Gebhart, 1986a, 1986b; Miller and Proudfit, 1990; Jones, 1991; West et al., 1993). 
A
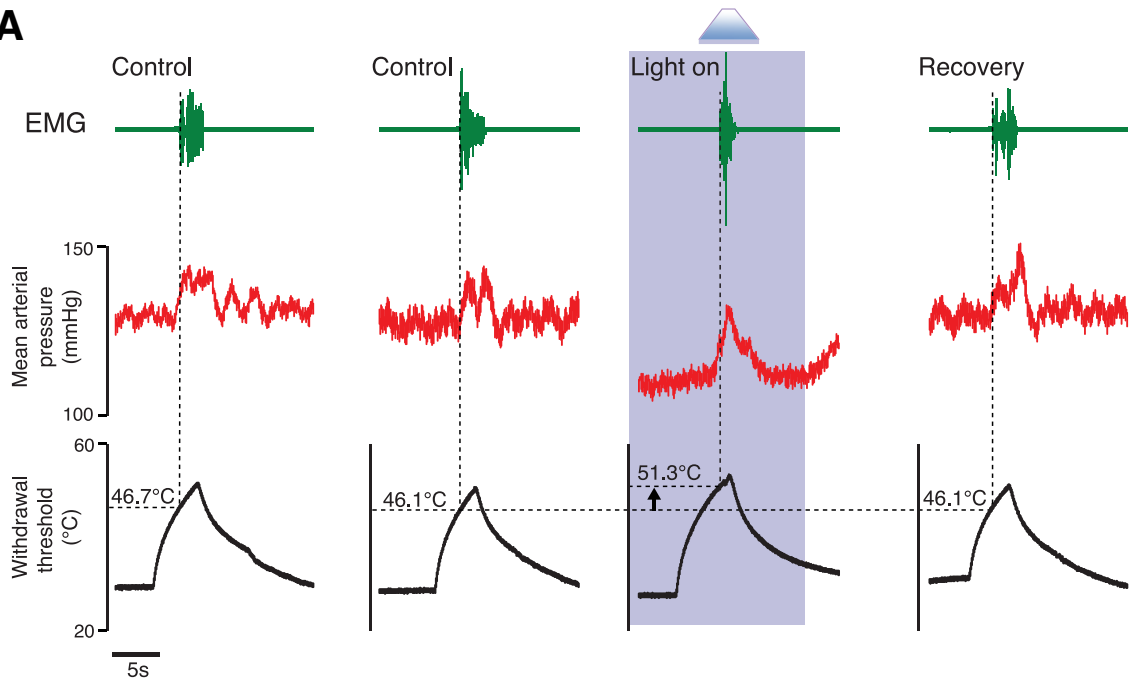

B

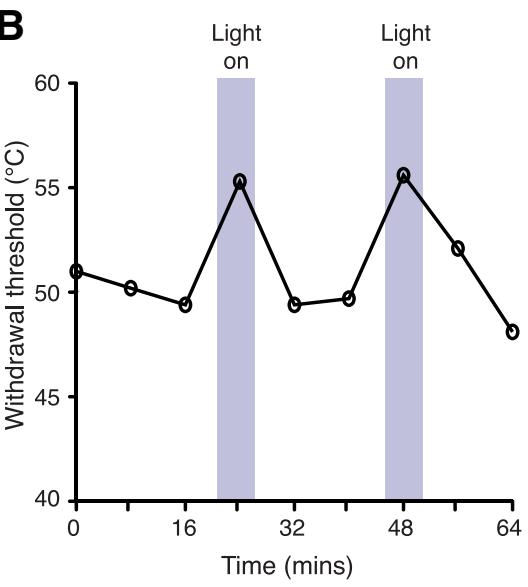

c

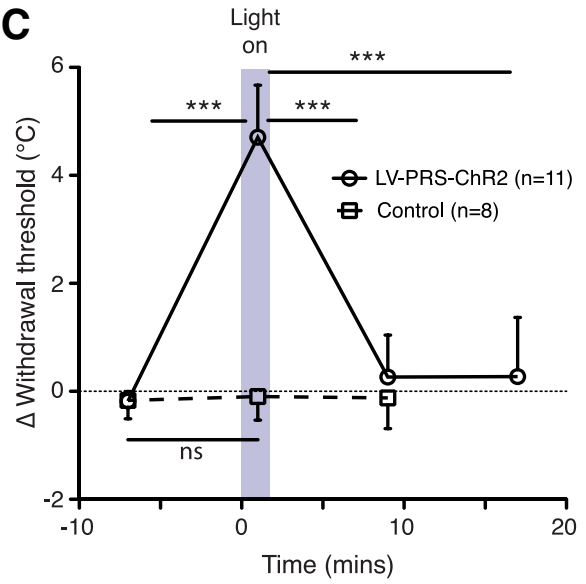

D

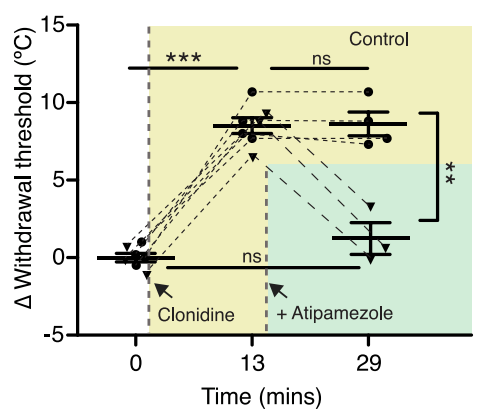

E

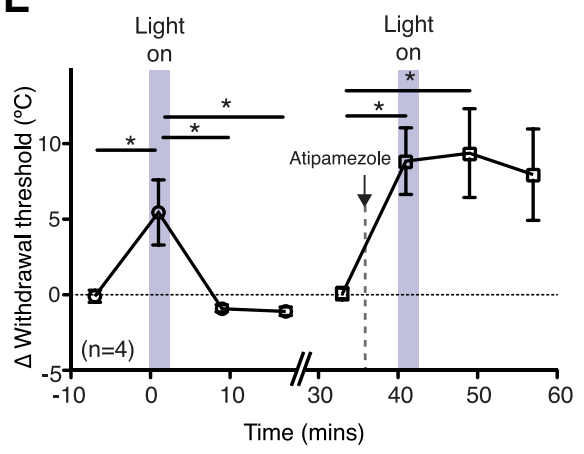

Figure 6. LC optoactivation is antinociceptive. $A$, Withdrawal responses to the thermal stimulus with a burst of EMG activity recorded from biceps femoris corresponding to a withdrawal threshold of $\sim 46^{\circ} \mathrm{C}$ under baseline conditions (X2). Optoactivation of the LC ( $30 \mathrm{~mW}$ for 60 s before heat ramp, blue box) increased the withdrawal threshold temperature by $5^{\circ} \mathrm{C}$, which fully reversed back to control $8 \mathrm{~min}$ later. $\boldsymbol{B}$, Plot of change in withdrawal threshold with repeated optoactivation (blue bars) from another single experiment with a return back to baseline within $10 \mathrm{~min}$. C, Pooled data showing LC optoactivation to robustly increase withdrawal thresholds by $>4^{\circ} \mathrm{C}$ (degrees change from baseline), which is consistent with an antinociceptive action $(n=11)$ compared with controls (no viral transduction, $n=8$ ). D, Intrathecal clonidine (750 ng), an $\alpha 2$-agonist, significantly increased withdrawal thresholds ( $p<0.001$, paired $t$ test, $n=7$ ), which remained elevated for $>30$ min. However, this increase in withdrawal threshold was reversed back to baseline in the group of animals given atipamezole ( $50 \mu \mathrm{g}, \mathrm{i} . \mathrm{t}, n=3, p<0.01$, unpaired $t$ test). $\boldsymbol{E}$, In contrast, intrathecal atipamezole $(100 \mu \mathrm{g})$ did not prevent the antinociceptive effects of $L C$ optoactivation $(n=4)$. rmANOVA with Bonferroni's posttest, ${ }^{* *} p<0.001,{ }^{* *} p<0.01,{ }^{*} p<0.05$.

Optoactivation of the LC produced graded (according to stimulus intensity and duration), reproducible falls in mean arterial pressure ( $30 \mathrm{~mW}, 25 \pm 5 \mathrm{mmHg}, p<0.0001$, repeatedmeasures ANOVA [rmANOVA] with Bonferroni's posttest, $n=$
11 ; Fig. $5 A, B)$, which was not seen in control animals $(p>0.05, n=7)$. The depressor response was also related to optical fiber depth such that its magnitude increased as the LC was approached (Fig. 5C). A similar depressor effect has been seen on microinjection of glutamatergic or cholinergic agonists (Jones and Gebhart, 1986b; Sved and Felsten, 1987) and is mediated by sympathoinhibition. These studies contrasted with electrical stimulation of the LC that was found to produce a pressor effect thought to be due to an offtarget action on fibers of passage. This depressor effect of LC optoactivation therefore supports the efficacy/selectivity of our stimulation methodology.

LC activation exerted a strong antinociceptive effect (seen in $55 \%$ of rats, $n=$ $11 / 20$ ) with repeatable, substantial, increases in thermal withdrawal thresholds $\left(+4.7 \pm 1.0^{\circ} \mathrm{C}, p<0.0001\right.$, rmANOVA with Bonferroni's posttest, $n=11 / 20$; Fig. $6 A-C)$. These changes were seen to reverse back to baseline within $10 \mathrm{~min}$. No change in threshold was seen in control rats in which the same laser stimulus was applied to the LC ( $n=8$; Fig. $6 C)$. After repeated optoactivation of the LC (typically $>3 \times$ ), a prolonged increase in the withdrawal threshold was sometimes observed that did not recover over the time course of the experiment $(>2 \mathrm{~h})$.

Intrathecal administration of clonidine $(0.75 \mu \mathrm{g})$ also increased the withdrawal threshold in naive animals $(+7.8 \pm$ $0.8^{\circ} \mathrm{C}, p<0.0001$, rmANOVA with Bonferroni's posttest, $n=7$; Fig. $6 D$ ), which was not seen in saline controls $(-0.5 \pm$ $0.5^{\circ} \mathrm{C}$, n.s., $n=5$ ), demonstrating the sensitivity of the thermal withdrawal assay to spinal $\alpha 2$-agonists. This action of clonidine was reliably reversed by atipamezole (50 $\mu$ g, i.t.), a selective $\alpha 2$-antagonist; clonidine no longer produced a significant change in withdrawal threshold $(+1.0 \pm$ $\left.1.0^{\circ} \mathrm{C}\right)$. However, in LC-transduced animals, atipamezole ( $100 \mu \mathrm{g}$, i.t.) failed to attenuate the LC-evoked antinociception $\left(+8.9 \pm 2.2^{\circ} \mathrm{C}, p<0.05\right.$, rmANOVA with Bonferroni's posttest, $n=4$; Fig. $6 E$ ), suggesting that this action was not mediated by spinal $\alpha 2$-adrenoceptors. Indeed, the atipamezole appeared to prolong the duration of the stimulation-evoked increase in threshold, which no longer returned to baseline (within $30 \mathrm{~min}$ ).

In contrast, $45 \%$ of the animals showed pronociceptive effects on optoactivation of the LC with reversible decreases in thermal threshold $\left(-4.4 \pm 0.7^{\circ} \mathrm{C}, p<0.0001\right.$, rmANOVA with Bonferroni's posttest, $n=9 / 20$; Fig. 7). In individual experiments, only an increase or a decrease in threshold was seen after LC optoactivation at the 
initial fiber site. We reviewed the experimental parameters for the antinociceptive versus pronociceptive actions $(n=11$ and 9 , respectively) and there was no difference in anesthetic infusion rate (alfaxalone $11.7 \pm 0.8$ vs $10.0 \pm 1.0 \mathrm{mg} / \mathrm{h}, p=$ 0.17 , unpaired $t$ test), which was titrated against the paw withdrawal response; in hindpaw skin surface temperature $\left(27.7 \pm 0.5\right.$ vs $27.8 \pm 0.6^{\circ} \mathrm{C}$ respectively, $p=0.9$, unpaired $t$ test); or in baseline thermal withdrawal thresholds (49.2 \pm 1.1 vs $51.5 \pm 0.3^{\circ} \mathrm{C}$, respectively, $p=0.13$, unpaired $t$ test). Similarly there was no difference in the magnitude of the depressor responses to LC activation in preparations showing antinociceptive $(27 \pm 4$ $\mathrm{mmHg}, n=7$ ) or pronociceptive actions (22 $\pm 9 \mathrm{mmHg}, n=4, p=0.78$, unpaired $t$ test). The depressor effect was not associated with significant changes in hindpaw skin temperature $(27.9 \pm 0.4$ vs $28.2 \pm 0.4^{\circ} \mathrm{C}, p=0.12$, paired $t$ test, $n=$ 9). Comparable studies using heat ramps have shown that similar changes in arterial pressure associated with PAG stimulation were not responsible for the antinociceptive effects (McMullan and Lumb, 2006).

Post hoc histological analysis suggested that different subpopulations of LC neurons were labeled in those animals showing antinociceptive effects (with a ventral predominance extending down to the subceruleus) compared with those showing pronociceptive effects (largely restricted to a more dorsal location in the body of the LC proper; Fig. $8 A$ ). Similarly analysis of the distribution of the successful fiber stimulation sites also demonstrated that the pronociceptive actions tended to be evoked from a more dorsal position $(5.25 \pm 0.2$ vs $5.6 \pm 0.1 \mathrm{~mm}$, respectively, $p=$ 0.04 , unpaired $t$ test; Fig. $8 B$ ). Having noted the relationship of LC-evoked response to the placement of the optical fiber, we changed our experimental protocol and intentionally advanced the fiber (by $500 \mu \mathrm{m})$ beyond its initial stimulating position $(n=$ 3 ) and observed a switch from pronociception $\left(-3.3 \pm 0.1^{\circ} \mathrm{C}\right.$, $p<0.05$, rmANOVA with Bonferroni's posttest, $n=3)$ to antinociception $(+2.9 \pm 0.3, p<0.01)$ as the fiber was moved to a deeper position (Fig. 8C). In one experiment, this was found to be reversible back to antinociception on withdrawal of the fiber back to its original position.

\section{Discussion}

The LC is proposed to play an important role in an endogenous descending pain control circuit (Jones, 1991; Millan, 2002; Pertovaara, 2006). Given that this NAergic circuit component appears to be functionally underactive in chronic neuropathic pain (Howorth et al., 2009b; Alba-Delgado et al., 2012; Hughes et al., 2013), we have been interested in exploring the nature of this deficit and developing strategies to augment its activity. In this study, we have tested whether the expression of hChR2 in NAergic neurons (Carter et al., 2010; Zhang et al., 2010) will permit selective, specific, temporally discrete activation of the LC and have assessed its role in the control of thermal nociception.

We assayed the effect of LC activation on the nocifensive withdrawal response to a hindpaw thermal heat stimulus (McMullan et al., 2004). Consistent with a role in endogenous analgesia, we show that activation of the LC can produce a substantial, tempo- rally discrete antinociceptive effect. We also describe a novel acute pronociceptive effect of LC activation using similar stimulation parameters and propose that distinct subpopulations of neurons in the LC drive these opposing actions. These findings demonstrate bidirectional modulation of nociception by the LC-a characteristic that has long been known for other brainstem descending control areas such as the rostral ventromedial medulla (RVM; Heinricher et al., 2009; Ossipov et al., 2010) and the periaqueductal gray (PAG; Basbaum and Fields, 1978; Lovick and Bandler, 2005). Bidirectional modulation of nociception has also been reported previously for the A7 NAergic cell group after microinjection of opioids (Holden et al., 1999) or $\mathrm{GABA}_{\mathrm{A}}$ antagonists (Nuseir and Proudfit, 2000).

The LC extends widespread projections and is the main source of NA for much of the CNS (Dahlstrom and Fuxe, 1964; Foote and Morrison, 1987; Aston-Jones, 2004). It is a relatively small structure with $\sim 3000$ neurons in the rat (Loughlin et al., 1986a) and, although these cells are considered homogenous with respect to their NAergic neurochemistry, they can be divided into several different subgroups based on cell morphology and efferent targets (Loughlin et al., 1986b; Berridge and Waterhouse, 2003; Aston-Jones, 2004). With respect to pain control, it is the descending projections to the spinal dorsal horn that have received the most attention (Jones, 1991; Millan, 2002; Pertovaara, 2006) and these are predominantly located in the ventral pole and in the subceruleus (Westlund et al., 1983; Howorth et al., 2009a; Bruinstroop et al., 2012). Previous studies have shown that focal stimulation (electrical and/or chemical) of the LC region can produce antinociceptive effects (Margalit and Segal, 1979; Jones and Gebhart, 1986b; Jones, 1991; West et al., 1993). We have now shown directly that LC neuronal activation is antinociceptive through the use of an optogenetic approach that specifically targets the NAergic neurons and removes the potential confound of stimulation of axons of passage or indirect activation of neighboring neurons via chemical spread. Therefore, our findings reinforce the notion that the LC is part of the endogenous antinociceptive control system.

The LC-stimulation induced antinociception was mimicked by intrathecal administration of the $\alpha 2$-agonist clonidine, but was not blocked by intrathecal administration of the $\alpha 2$ - 
A
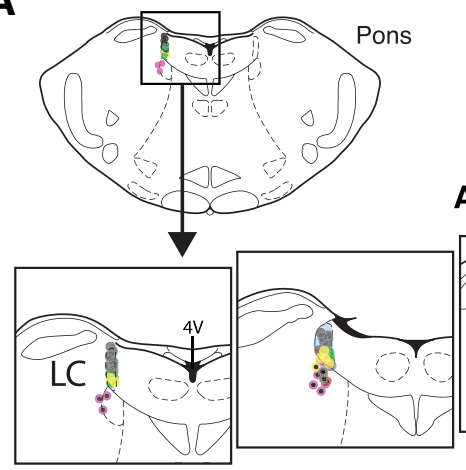

$-9.48 m m$

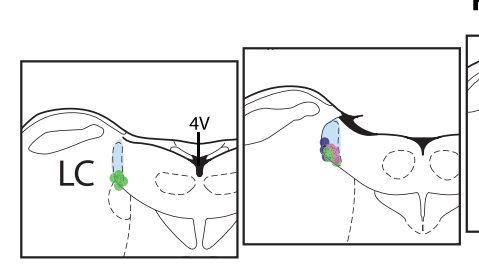

$-9.48 m m$

B

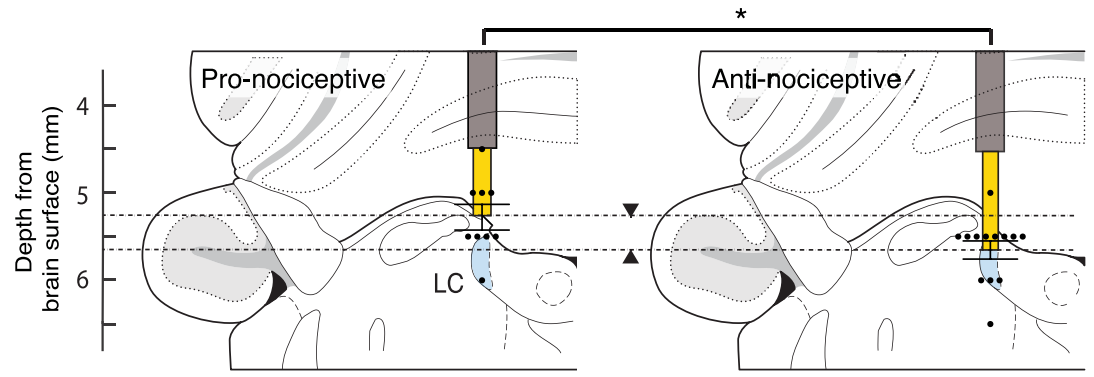

C

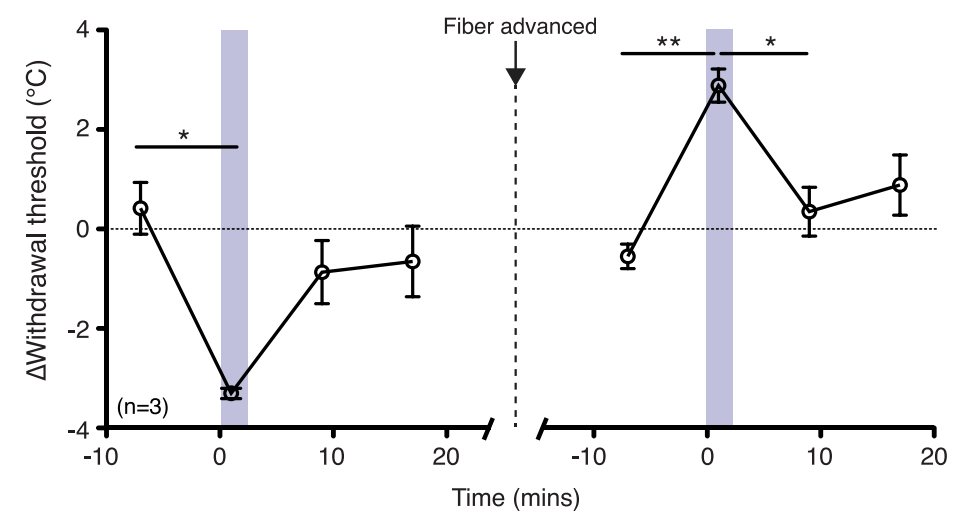

Figure 8. Subpopulations of $\mathrm{LC} /$ subceruleus neurons drive antinociception versus pronociception. $\boldsymbol{A}$, Schematic illustrating the position of $\mathrm{LV}$-transduced neurons from rats showing antinociception ( $n=7$, top row) and pronociception ( $n=4$, bottom row) overlaid on atlas sections (Paxinos and Watson, 2005). Each color represents a different animal, each dot corresponds to a neuron in a $40 \mu \mathrm{m}$ section, and dark core dots are outside the LC. Animals showing antinociception had LV-transduced LC neurons with a ventral predominance clearly extending to the subceruleus, whereas transduction was mainly restricted to midcaudal LC proper in those showing pronociceptive effects. $\boldsymbol{B}$, Graph showing the fiber stimulation site (depth from cerebellar surface) for the pronociceptive actions, which were more dorsal than those sites with antinociceptive actions (left and right, respectively, ${ }^{*} p<0.05$, unpaired $t$ test). $C$, By changing our recording protocol to allow the fiber position to be advanced beyond the first response site (by $500 \mu \mathrm{m})$, we observed a switch in the response from pronociception to antinociception $(n=3)$. rmANOVA followed by Bonferroni's posttest, ${ }^{* *} p<0.01,{ }^{*} p<0.05$.

antagonist atipamezole-indeed, this dose appeared to enhance the antinociceptive action. This is counter to previous reports showing that intrathecal $\alpha 2$-antagonists block LC-stimulusevoked analgesia (Jones and Gebhart, 1986b; Miller and Proudfit, 1990; West et al., 1993). We used a substantial dose of atipam- ezole $(100 \mu \mathrm{g})$ that was double that needed to completely reverse the effects of intrathecal clonidine. One previous LC stimulation study reported analgesic actions that were resistant to an intrathecal $\alpha 2$-antagonist, idazoxan (West et al., 1993). It may be relevant to note that atipamezole and idazoxan have a much higher $\alpha 2: \alpha 1$ selectivity ratio than yohimbine (Pertovaara et al., 2005), which was used by many of the early studies (Jones and Gebhart, 1986b; Miller and Proudfit, 1990; West et al., 1993). It remains to be determined whether the antinociceptive actions of LC activation may be mediated by another mechanism, such as enhancement of inhibitory transmission by $\alpha 1$ receptors at a spinal level (Baba et al., 2000; Gassner et al., 2009; Funai et al., 2014). It may also be relevant that the LC neurons are capable of releasing other transmitter substances such as galanin, neuropeptide $\mathrm{Y}$, and ATP in addition to noradrenaline (Holets et al., 1988); spinal galanin in particular has been associated with antinociceptive actions (Hua et al., 2004). Alternatively, the LC may have a supraspinal action via a relay in the RVM (Aston-Jones, 2004) to inhibit the spinal nociception through opioid release (Margalit and Segal, 1979; Miller and Proudfit, 1990) or perhaps on ascending nociceptive pathways, for example, at a thalamic level (Voisin et al., 2005).

Counter to our expectation, we also demonstrated a potent LC-mediated pronociceptive action that reduced the thermal withdrawal threshold. Although the LC is predominantly associated with pain inhibition, there is some evidence to suggest that it may also play a role in the facilitation of chronic pain. Brightwell and Taylor (2009) showed that the LC facilitates the maintenance of neuropathic pain. Similarly Martins et al. (2010) reported a facilitatory effect of the LC on neuropathic pain mediated via the medullary dorsal reticular nucleus. In addition, the second phase behavioral responses to formalin injection were found to be reduced after neurotoxic LC lesions (Martin et al., 1999). In contrast, we reported previously that selective inhibition of the pontospinal LC enhances the response to formalin (Howorth et al., 2009b), which raises the possibility of anatomically distinct LC effects on nociceptive processing.

By mapping of the distribution of the transduced neurons, we demonstrated that a larger proportion of the fluorescent neurons were located in the ventral LC and subceruleus in those experiments showing antinociceptive responses. Similarly, we found that the optic fiber placement was deeper in experiments showing antinociceptive responses. We 
subsequently showed both pronociceptive and antinociceptive actions in the same experiment by varying fiber depth. This suggests that the pronociceptive and antinociceptive actions are mediated by distinct subpopulations of LC neurons, with the antinociceptive effect originating from neurons in the ventral region. The balance of pronociceptive versus antinociceptive actions within any given experiment was thus a function of the distribution of the transduced neurons within the LC and of the fiber position relative to the $\mathrm{LC}$. These data support the principle that the antinociception may be via a spinally mediated mechanism, because the ventral LC and subceruleus are known to project to the dorsal horn of the spinal cord (Westlund et al., 1983; Loughlin et al., 1986a; Howorth et al., 2009a; Bruinstroop et al., 2012), although it is also apparent that some of the spinally projecting LC neurons also innervate supratentorial structures (Guyenet, 1980; Leanza et al., 1989; Howorth et al., 2009a), forming a neural substrate for a multilevel influence upon pain processing. The detailed dissection of these LC modules will require more specific transduction methods that allow selective targeting of these subpopulations (Howorth et al., 2009a; Osakada et al., 2011) or activation of their terminals by focal spinal illumination.

We show here that the LC neurons are activated by noxious heat stimulation, which is consistent with a role in the modulation of nociception. Although the LC has long been known to respond to noxious mechanical stimulation (Cedarbaum and Aghajanian, 1976) and to prolonged thermal stimuli (Elam et al., 1986; Hajós et al., 1986), we have extended this finding using the heat ramp withdrawal response assay. With this graded stimulus, we show that $\mathrm{LC}$ activation occurs just as the temperature reaches the noxious range (i.e., as it becomes salient) immediately before the withdrawal response; therefore, conceptually, the LC neurons could act to attenuate the onward transmission of the nociceptive information. However, this could be part of an alerting or arousal response to the stimulus as part of a facilitatory action, as has been reported for "on cells" in the RVM (Fields et al., 1991).

The LC is implicated in the regulation of attention, sleepwake cycles, mood, and motivation mediated by interlinked, coordinated effects across distinct neural systems (Berridge and Waterhouse, 2003; Sara, 2009). Within this framework, we hypothesize that the pronociceptive action may be mediated by a subset of LC neurons also responsible for promoting wakefulness and attention (Carter et al., 2010) as part of a system to focus cognitive resources. In contrast, the antinociceptive actions may be mediated by a distinct subset that are engaged in a different behavioral context such as the "fight or flight" response to attenuate the incoming nociceptive signal to deploy defensive or escape behaviors (Heinricher et al., 2009). Bidirectional actions of the LC have been documented for other sensory modalities, in which this is thought to improve acuity (for review, see Berridge and Waterhouse, 2003; Sara, 2009; Sara and Bouret, 2012) as part of a salience detection mechanism. Given that a noxious stimulus is by definition an event with high salience (Legrain et al., 2011), it is perhaps not surprising that such bimodal modulation of nociceptive responses could be demonstrated by direct activation of the LC. This dual role of the LC may account in part for the limited efficacy of NA reuptake inhibition in the treatment of chronic pain (Finnerup et al., 2010), in which the net effect may be the sum of opposing actions, and also suggests that therapeutically targeting the whole LC for neuromodulation is unlikely to yield "pure" antinociceptive actions.

\section{References}

Abbott SB, Stornetta RL, Fortuna MG, Depuy SD, West GH, Harris TE, Guyenet PG (2009) Photostimulation of retrotrapezoid nucleus phox $2 \mathrm{~b}$-expressing neurons in vivo produces long-lasting activation of breathing in rats. J Neurosci 29:5806-5819. CrossRef Medline

Aghajanian GK, Cedarbaum JM, Wang RY (1977) Evidence for norepinephrine-mediated collateral inhibition of locus coeruleus neurons. Brain Res 136:570-577. CrossRef Medline

Alba-Delgado C, Mico JA, Sánchez-Blázquez P, Berrocoso E (2012) Analgesic antidepressants promote the responsiveness of locus coeruleus neurons to noxious stimulation: implications for neuropathic pain. Pain 153: 1438-1449. CrossRef Medline

Aston-Jones G (2004) Locus ceruleus, A5 and A7 noradrenergic cell groups. In: The rat nervous system, Ed 3 (Paxinos G, ed), pp 259-294. San Diego, London: Elsevier.

Baba H, Goldstein PA, Okamoto M, Kohno T, Ataka T, Yoshimura M, Shimoji K (2000) Norepinephrine facilitates inhibitory transmission in substantia gelatinosa of adult rat spinal cord (part 2): effects on somatodendritic sites of GABAergic neurons. Anesthesiology 92:485-492. CrossRef Medline

Basbaum AI, Fields HL (1978) Endogenous pain control mechanisms: review and hypothesis. Ann Neurol 4:451-462. CrossRef Medline

Berridge CW, Waterhouse BD (2003) The locus coeruleus-noradrenergic system: modulation of behavioral state and state-dependent cognitive processes. Brain Res Brain Res Rev 42:33-84. CrossRef Medline

Boyden ES, Zhang F, Bamberg E, Nagel G, Deisseroth K (2005) Millisecondtimescale, genetically targeted optical control of neural activity. Nat Neurosci 8:1263-1268. CrossRef Medline

Brightwell JJ, Taylor BK (2009) Noradrenergic neurons in the locus coeruleus contribute to neuropathic pain. Neuroscience 160:174-185. CrossRef Medline

Bruinstroop E, Cano G, Vanderhorst VG, Cavalcante JC, Wirth J, SenaEsteves M, Saper CB (2012) Spinal projections of the A5, A6 (locus coeruleus), and A7 noradrenergic cell groups in rats. J Comp Neurol 520: 1985-2001. CrossRef Medline

Brunet JF, Pattyn A (2002) Phox2 genes-from patterning to connectivity. Curr Opin Genet Dev 12:435-440. CrossRef Medline

Carter ME, Yizhar O, Chikahisa S, Nguyen H, Adamantidis A, Nishino S, Deisseroth K, de Lecea L (2010) Tuning arousal with optogenetic modulation of locus coeruleus neurons. Nat Neurosci 13:1526-1533. CrossRef Medline

Cedarbaum JM, Aghajanian GK (1976) Noradrenergic neurons of the locus coeruleus: inhibition by epinephrine and activation by the alphaantagonist piperoxane. Brain Res 112:413-419. CrossRef Medline

Cedarbaum JM, Aghajanian GK (1978) Activation of locus coeruleus neurons by peripheral stimuli: modulation by a collateral inhibitory mechanism. Life Sci 23:1383-1392. CrossRef Medline

Coleman JE, Huentelman MJ, Kasparov S, Metcalfe BL, Paton JF, Katovich MJ, Semple-Rowland SL, Raizada MK (2003) Efficient large-scale production and concentration of HIV-1-based lentiviral vectors for use in vivo. Physiol Genomics 12:221-228. Medline

Crawley JN, Roth RH, Maas JW (1979) Locus coeruleus stimulation increases noradrenergic metabolite levels in rat spinal cord. Brain Res 166: 180-184. CrossRef Medline

Dahlstrom A, Fuxe K (1964) Evidence for the existence of monoaminecontaining neurons in the central nervous system. Acta Physiol Scand Suppl 232:1-55. Medline

Dodt HU, Zieglgänsberger W (1990) Visualizing unstained neurons in living brain slices by infrared DIC- videomicroscopy. Brain Res 537:333336. CrossRef Medline

Elam M, Svensson TH, Thorén P (1986) Locus coeruleus neurons and sympathetic nerves: activation by cutaneous sensory afferents. Brain Res 366 : 254-261. CrossRef Medline

Fields H (2004) State-dependent opioid control of pain. Nat Rev Neurosci 5:565-575. CrossRef Medline

Fields HL, Heinricher MM, Mason P (1991) Neurotransmitters in nociceptive modulatory circuits. Annu Rev Neurosci 14:219-245. CrossRef Medline

Finnerup NB, Sindrup SH, Jensen TS (2010) The evidence for pharmacological treatment of neuropathic pain. Pain 150:573-581. CrossRef Medline 
Foote SL, Morrison JH (1987) Extrathalamic modulation of cortical function. Annu Rev Neurosci 10:67-95. CrossRef Medline

Funai Y, Pickering AE, Uta D, Nishikawa K, Mori T, Asada A, Imoto K, Furue H (2014) Systemic dexmedetomidine augments inhibitory synaptic transmission in the superficial dorsal horn through activation of descending noradrenergic control: an in vivo patch-clamp analysis of analgesic mechanisms. Pain 155:617-628. CrossRef Medline

Gassner M, Ruscheweyh R, Sandkühler J (2009) Direct excitation of spinal GABAergic interneurons by noradrenaline. Pain 145:204-210. CrossRef Medline

Guyenet PG (1980) The coeruleospinal noradrenergic neurons: anatomical and electrophysiological studies in the rat. Brain Res 189:121-133. CrossRef Medline

Hajós M, Engberg G, Elam M (1986) Reduced responsiveness of locus coeruleus neurons to cutaneous thermal stimuli in capsaicin-treated rats. Neurosci Lett 70:382-387. CrossRef Medline

Hammond DL, Yaksh TL (1984) Antagonism of stimulation-produced antinociception by intrathecal administration of methysergide or phentolamine. Brain Res 298:329-337. CrossRef Medline

Hassenbusch SJ, Gunes S, Wachsman S, Willis KD (2002) Intrathecal clonidine in the treatment of intractable pain: a phase I/II study. Pain Med 3:85-91. CrossRef Medline

Hayashida K, Clayton BA, Johnson JE, Eisenach JC (2008) Brain derived nerve growth factor induces spinal noradrenergic fiber sprouting and enhances clonidine analgesia following nerve injury in rats. Pain 136:348355. CrossRef Medline

Heinricher MM, Tavares I, Leith JL, Lumb BM (2009) Descending control of nociception: Specificity, recruitment and plasticity. Brain Res Rev 60: 214-225. CrossRef Medline

Hentall ID, Mesigil R, Pinzon A, Noga BR (2003) Temporal and spatial profiles of pontine-evoked monoamine release in the rat's spinal cord. J Neurophysiol 89:2943-2951. CrossRef Medline

Hewinson J, Paton JF, Kasparov S (2013) Viral gene delivery: optimized protocol for production of high titer lentiviral vectors. Methods Mol Biol 998:65-75. CrossRef Medline

Holden JE, Schwartz EJ, Proudfit HK (1999) Microinjection of morphine in the A7 catecholamine cell group produces opposing effects on nociception that are mediated by alpha1- and alpha2-adrenoceptors. Neuroscience 91:979-990. CrossRef Medline

Holets VR, Hökfelt T, Rökaeus A, Terenius L, Goldstein M (1988) Locus coeruleus neurons in the rat containing neuropeptide $\mathrm{Y}$, tyrosine hydroxylase or galanin and their efferent projections to the spinal cord, cerebral cortex and hypothalamus. Neuroscience 24:893-906. CrossRef Medline

Howorth PW, Teschemacher AG, Pickering AE (2009a) Retrograde adenoviral vector targeting of nociresponsive pontospinal noradrenergic neurons in the rat in vivo. J Comp Neurol 512:141-157. CrossRef Medline

Howorth PW, Thornton SR, O'Brien V, Smith WD, Nikiforova N, Teschemacher AG, Pickering AE (2009b) Retrograde viral vector-mediated inhibition of pontospinal noradrenergic neurons causes hyperalgesia in rats. J Neurosci 29:12855-12864. CrossRef Medline

Hua XY, Hayes CS, Hofer A, Fitzsimmons B, Kilk K, Langel U, Bartfai T, Yaksh TL (2004) Galanin acts at GalR1 receptors in spinal antinociception: synergy with morphine and AP-5. J Pharmacol Exp Ther 308:574582. CrossRef Medline

Hughes SW, Hickey L, Hulse RP, Lumb BM, Pickering AE (2013) Endogenous analgesic action of the pontospinal noradrenergic system spatially restricts and temporally delays the progression of neuropathic pain following tibial nerve injury. Pain 154:1680-1690. CrossRef Medline

Hwang DY, Carlezon WA Jr, Isacson O, Kim KS (2001) A high-efficiency synthetic promoter that drives transgene expression selectively in noradrenergic neurons. Hum Gene Ther 12:1731-1740. CrossRef Medline

Jones SL (1991) Descending noradrenergic influences on pain. Prog Brain Res 88:381-394. CrossRef Medline

Jones SL, Gebhart GF (1986a) Quantitative characterization of ceruleospinal inhibition of nociceptive transmission in the rat. J Neurophysiol 56: 1397-1410. Medline

Jones SL, Gebhart GF (1986b) Characterization of coeruleospinal inhibition of the nociceptive tail-flick reflex in the rat: mediation by spinal alpha 2-adrenoceptors. Brain Res 364:315-330. CrossRef Medline

Kawasaki Y, Kumamoto E, Furue H, Yoshimura M (2003) Alpha 2 adrenoceptor-mediated presynaptic inhibition of primary afferent gluta- matergic transmission in rat substantia gelatinosa neurons. Anesthesiology 98:682-689. CrossRef Medline

Leanza G, Pellitteri R, Russo A, Stanzani S (1989) Branching projections from subcoeruleus area neurons to medial preoptic area and cervical spinal cord revealed by double retrograde neuronal labeling. Neurosci Lett 103:11-16. CrossRef Medline

Legrain V, Iannetti GD, Plaghki L, Mouraux A (2011) The pain matrix reloaded: a salience detection system for the body. Prog Neurobiol 93:111124. CrossRef Medline

Liu BH, Yang Y, Paton JF, Li F, Boulaire J, Kasparov S, Wang S (2006) GAL4-NF-kappaB fusion protein augments transgene expression from neuronal promoters in the rat brain. Mol Ther 14:872-882. CrossRef Medline

Lonergan T, Teschemacher AG, Hwang DY, Kim KS, Pickering AE, Kasparov S (2005) Targeting brain stem centers of cardiovascular control using adenoviral vectors: impact of promoters on transgene expression. Physiol Genomics 20:165-172. CrossRef Medline

Loughlin SE, Foote SL, Bloom FE (1986a) Efferent projections of nucleus locus coeruleus: topographic organization of cells of origin demonstrated by three-dimensional reconstruction. Neuroscience 18:291-306. CrossRef Medline

Loughlin SE, Foote SL, Grzanna R (1986b) Efferent projections of nucleus locus coeruleus: morphologic subpopulations have different efferent targets. Neuroscience 18:307-319. CrossRef Medline

Lovick TA, Bandler R (2005) The organisation of the midbrain periaqueductal grey and the integration of pain behaviours. In: The neurobiology of pain-molecular and cellular neurobiology (Hunt S, Koltzenburg M, eds), pp 267-287. Oxford: OUP.

Ma W, Eisenach JC (2003) Chronic constriction injury of sciatic nerve induces the up-regulation of descending inhibitory noradrenergic innervation to the lumbar dorsal horn of mice. Brain Res 970:110-118. CrossRef Medline

Margalit D, Segal M (1979) A pharmacologic study of analgesia produced by stimulation of the nucleus locus coeruleus. Psychopharmacology 62:169173. CrossRef Medline

Martin WJ, Gupta NK, Loo CM, Rohde DS, Basbaum AI (1999) Differential effects of neurotoxic destruction of descending noradrenergic pathways on acute and persistent nociceptive processing. Pain 80:57-65. CrossRef Medline

Martins I, Costa-Araújo S, Fadel J, Wilson SP, Lima D, Tavares I (2010) Reversal of neuropathic pain by HSV-1-mediated decrease of noradrenaline in a pain facilitatory area of the brain. Pain 151:137-145. CrossRef Medline

McAllen RM, Salo LM, Paton JF, Pickering AE (2011) Processing of central and reflex vagal drives by rat cardiac ganglion neurones: an intracellular analysis. J Physiol 589:5801-5818. CrossRef Medline

McMullan S, Lumb BM (2006) Midbrain control of spinal nociception discriminates between responses evoked by myelinated and unmyelinated heat nociceptors in the rat. Pain 124:59-68. CrossRef Medline

McMullan S, Simpson DA, Lumb BM (2004) A reliable method for the preferential activation of C- or A-fibre heat nociceptors. J Neurosci Methods 138:133-139. CrossRef Medline

Melzack R, Wall PD, Ty TC (1982) Acute pain in an emergency clinic: latency of onset and descriptor patterns related to different injuries. Pain 14:33-43. CrossRef Medline

Millan MJ (2002) Descending control of pain. Prog Neurobiol 66:355-474. CrossRef Medline

Miller JF, Proudfit HK (1990) Antagonism of stimulation-produced antinociception from ventrolateral pontine sites by intrathecal administration of alpha-adrenergic antagonists and naloxone. Brain Res 530:20-34. CrossRef Medline

North RA, Yoshimura M (1984) The actions of noradrenaline on neurones of the rat substantia gelatinosa in vitro. J Physiol 349:43-55. Medline

Nuseir K, Proudfit HK (2000) Bidirectional modulation of nociception by GABA neurons in the dorsolateral pontine tegmentum that tonically inhibit spinally projecting noradrenergic A7 neurons. Neuroscience 96: 773-783. CrossRef Medline

Osakada F, Mori T, Cetin AH, Marshel JH, Virgen B, Callaway EM (2011) New rabies virus variants for monitoring and manipulating activity and gene expression in defined neural circuits. Neuron 71:617-631. CrossRef Medline 
Ossipov MH, Dussor GO, Porreca F (2010) Central modulation of pain. J Clin Invest 120:3779-3787. CrossRef Medline

Paton JF (1996) A working heart-brainstem preparation of the mouse. J Neurosci Methods 65:63-68. CrossRef Medline

Paxinos G, Watson C (2005) The rat brain in stereotaxic coordinates, pp 166. San Diego: Elsevier.

Pertovaara A (2006) Noradrenergic pain modulation. Prog Neurobiol 80: 53-83. CrossRef Medline

Pertovaara A, Haapalinna A, Sirviö J, Virtanen R (2005) Pharmacological properties, central nervous system effects, and potential therapeutic applications of atipamezole, a selective alpha2-adrenoceptor antagonist. CNS Drug Rev 11:273-288. Medline

Pickering AE, Boscan P, Paton JF (2003) Nociception attenuates parasympathetic but not sympathetic baroreflex via NK1 receptors in the rat nucleus tractus solitarii. J Physiol 551:589-599. CrossRef Medline

Reddy SV, Maderdrut JL, Yaksh TL (1980) Spinal cord pharmacology of adrenergic agonist-mediated antinociception. J Pharmacol Exp Ther 213: 525-533. Medline

Reynolds DV (1969) Surgery in the rat during electrical analgesia induced by focal brain stimulation. Science 164:444-445. CrossRef Medline

Sara SJ (2009) The locus coeruleus and noradrenergic modulation of cognition. Nat Rev Neurosci 10:211-223. CrossRef Medline

Sara SJ, Bouret S (2012) Orienting and reorienting: the locus coeruleus mediates cognition through arousal. Neuron 76:130-141. CrossRef Medline

Sonohata M, Furue H, Katafuchi T, Yasaka T, Doi A, Kumamoto E, Yo- shimura M (2004) Actions of noradrenaline on substantia gelatinosa neurones in the rat spinal cord revealed by in vivo patch recording. J Physiol 555:515-526. CrossRef Medline

Sugiyama D, Hur SW, Pickering AE, Kase D, Kim SJ, Kawamata M, Imoto K, Furue H (2012) In vivo patch-clamp recording from locus coeruleus neurones in the rat brainstem. J Physiol 590:2225-2231. CrossRef Medline

Sved AF, Felsten G (1987) Stimulation of the locus coeruleus decreases arterial pressure. Brain Res 414:119-132. CrossRef Medline

Tiveron MC, Hirsch MR, Brunet JF (1996) The expression pattern of the transcription factor Phox2 delineates synaptic pathways of the autonomic nervous system. J Neurosci 16:7649-7660. Medline

Voisin DL, Guy N, Chalus M, Dallel R (2005) Nociceptive stimulation activates locus coeruleus neurones projecting to the somatosensory thalamus in the rat. J Physiol 566:929-937. CrossRef Medline

West WL, Yeomans DC, Proudfit HK (1993) The function of noradrenergic neurons in mediating antinociception induced by electrical stimulation of the locus coeruleus in two different sources of Sprague-Dawley rats. Brain Res 626:127-135. CrossRef Medline

Westlund KN, Bowker RM, Ziegler MG, Coulter JD (1983) Noradrenergic projections to the spinal cord of the rat. Brain Res 263:15-31. CrossRef Medline

Zhang F, Gradinaru V, Adamantidis AR, Durand R, Airan RD, de Lecea L, Deisseroth K (2010) Optogenetic interrogation of neural circuits: technology for probing mammalian brain structures. Nat Protoc 5:439-456. CrossRef Medline 